\title{
Environmental DNA provides greater insight to biodiversity and ecosystem function compared to traditional approaches, via spatio-temporal nestedness and turnover partitioning
}

Mathew Seymour ( $\square$ mat.seymour@gmail.com )

Swedish University of Agricultural Sciences https://orcid.org/0000-0002-3654-4857

Francois Edwards

Bangor University https://orcid.org/0000-0001-9875-6663

Jack Cosby

NERC Centre for Ecology \& Hydrology

Pete Scarlet

CEH

Iliana Bista

Sanger

Francesca Brailsford

University of Western Australia https://orcid.org/0000-0002-1088-3527

Helen Glanville

Bangor University

Mark de Bruyn

University of Sydney https://orcid.org/0000-0003-1528-9604

Gary Carvalho

University of Wales at Bangor

Simon Creer

Bangor University https://orcid.org/0000-0003-3124-3550

Article

Keywords: COI, macroinvertebrates, chironomids, EPT, functional diversity

Posted Date: February 12th, 2021

DOl: https://doi.org/10.21203/rs.3.rs-82612/v3

License: (c) (1) This work is licensed under a Creative Commons Attribution 4.0 International License. Read Full License 
Version of Record: A version of this preprint was published at Communications Biology on May 3rd, 2021. See the published version at https://doi.org/10.1038/s42003-021-02031-2. 


\section{Abstract}

Rapidly assessing biodiversity is essential for environmental monitoring, however traditional approaches are limited in the scope needed for most ecological systems. Environmental DNA (eDNA) based assessment offers increased scope, while reducing cost and time, compared to traditional methods. Here we investigated the effects of landuse and seasonality on headwater community richness and functional diversity, to assess spatio-temporal dynamics between eDNA and traditional methods. Environmental DNA provided greater biodiversity resolution with both methods resulting in complementary findings. Community richness was seasonally linked, peaking in spring and summer, with temporal turnover having a greater effect on community composition compared to localized nestedness. Our assessment of ecosystem function shows community formation is driven by regional resource availability, implying regional management requirements. Our findings show that eDNA based ecological assessment is a powerful, rapid and effective assessment strategy that enables complex spatio-temporal studies of community diversity and ecosystem function previously unavailable by traditional means.

\section{Introduction}

Modern human development has drastically increased the speed at which we alter our physical and societal environments, which can have quick and drastic effects on our ecosystems and their function. We are often too slow to act on key changes in our environment, which makes the recovery and rehabilitation of healthy ecosystems more costly compared to programs that actively monitor ecosystems ${ }^{1}$. Active ecosystem monitoring relies greatly on the change in living biological communities (e.g. biodiversity) to assess changes in ecosystem function through community composition and ecosystem health, via community diversity ${ }^{2,3}$. However, despite the growing call to safeguard our natural ecosystems, we are currently experiencing a major decline in global biodiversity due to climate change and landuse alterations, which are outpacing current capabilities to actively monitor and respond to these threats ${ }^{4}$. It is therefore paramount that we develop more effective biodiversity assessment practices to increase our understanding of complex ecological systems and to promote ecosystem function and health ${ }^{5}$.

Accurate assessment of biodiversity relies on our understanding of the localized, spatial and temporal processes that shape changes in biodiversity in time and space ${ }^{6-8}$. Localized (i.e. site-specific) biodiversity assessments largely predominate current monitoring practices, whereby local environmental conditions (e.g. landuse) are relied on to explain changes in biodiversity richness. As changes in biodiversity are also influenced by spatial (e.g. dispersal) and temporal (e.g. phenology) factors, however, it is also essential to assess temporal and spatial community dynamics ${ }^{6}$. Furthermore, localized environmental filtering linked to biodiversity, which gives an indication of the general health of the ecosystem, can also be linked to ecosystem function if functional diversity of the localized biodiversity is available ${ }^{2}$. Biodiversity itself, can be quantified in many different ways, including through assessment of 
community richness or functional diversity. Richness is defined as the number of unique taxonomic units per site/sample. Richness is often positively correlated with heterogeneous environments, which is often

attributed to higher levels of functional diversity ${ }^{9-11}$. On the other hand, functional diversity directly quantifies the functionally disparate taxa within a community, and is becoming increasingly recognized as an important component of effective biomonitoring ${ }^{12}$. Additionally, differences in biodiversity (e.g. richness) between communities (e.g. sampling locations), commonly referred to as beta-diversity, determines if changes in biodiversity are influenced by more local or spatial factors ${ }^{13}$. Partitioning the variance of beta-diversity into recently derived nested and turnover components provides even greater insight into the processes that are driving inter-community homogenization or dissimilarity ${ }^{14}$. It is therefore important to also assess changes in biodiversity at the local level and between communities to monitor changes in ecosystem health, and to assess functional diversity when able to determine the status of the local and regional ecosystem function. Unfortunately, current monitoring methodologies and practices are often limited or forced to simplify methods to cope with limited computational power or to reduce cost ${ }^{15}$. To implement increased spatial and temporal biodiversity assessment we have to develop and utilize improved biodiversity assessment methodologies, as current practices are limited in their efficiency to generate the data needed to rapidly assess ecosystems, particularly at increased spatial and temporal resolution.

The application of environmental DNA (eDNA) and metabarcoding has recently shown to offer increased sampling resolution for biodiversity assessment efforts ${ }^{16-18}$, though for some species, specific traditional methods may outperform eDNA surveys ${ }^{19}$. Environmental DNA is extracted directly from an environmental sample (for example, water, soil or air) without prior isolation of the organisms themselves 20,21 . Sources of eDNA include sloughed skin cells, urine, feces, saliva or other bodily secretions, and could consist of both free molecules (extracellular DNA) and free cells ${ }^{22-25}$. Furthermore, eDNA collected from water samples has highly sensitive detection capability, is non-invasive to the sampled biota and not limited to physical environmental conditions (e.g. surface area or substrate types), thereby providing a wider sampling application with lower environmental impact, compared to traditional methods. It is important to note that eDNA capture can differ between environment types ${ }^{26,27}$, richness ${ }^{27}$ and within sites ${ }^{28}$, due to seasonal variation, ecology, or random sample variation. Variability in efficiencies of traditional sampling methods between locations is well known, however, as the number of eDNA studies increase, so does our ability to account for random variability in data, particularly compared to early eDNA-based studies ${ }^{18}$. Combined with high throughput sequencing (HTS) applications, such as metabarcoding, eDNA based sampling is rapidly being integrated into standard ecological monitoring practices. Previous eDNA biomonitoring studies in natural environments have assessed population and communities across spatial and temporal scales for rivers ${ }^{29-31}$, lakes ${ }^{28,32,33}$ and marine environments ${ }^{34-36}$. What is currently lacking is the link between functional and community diversity dynamics using eDNA across appropriate spatial and temporal scales. To develop and validate an eDNA-based approach 
to biodiversity assessment it is therefore important to develop hypotheses from our current understanding of functional and community principles and dynamics.

Headwater riverine biodiversity is one of the longest standing realms of ecology and a key component of current freshwater biomonitoring and assessment ${ }^{37}$. Riverine catchments are a crucial component of regional biodiversity that harbor high levels of diversity due to their hierarchical structure, environmentally diverse habitats, and resulting unique headwater communities ${ }^{37-39}$. Freshwater macroinvertebrates are an invaluable source of ecosystem assessment information as their community assembly (localized) are strongly linked to ecological conditions ${ }^{37,40}$. Additionally, changes in macroinvertebrate communities in time and space also provides important information for any changes to ecosystems, resulting from effects of landuse alteration, environmental, or other anthropogenic effects ${ }^{41}$. Current biomonitoring practices in rivers utilize biological indices derived from freshwater macroinvertebrates ${ }^{42}$. Freshwater macroinvertebrates represent a wide range of species and functional groups, which respond dynamically to temporal and spatial environmental filtering, thus providing a clear depiction of localized ecosystem function ${ }^{39,43,44}$. Specifically, functional feedings groups of freshwater macroinvertebrates provides direct assessment of nutrient cycling, productivity and decomposition ${ }^{44}$. Traditional taxonomic identification of freshwater macroinvertebrates, however, is largely limited to mature life stages that and can be difficult to identify or differentiate among similar species or genera ${ }^{42}$. The high level of taxonomic specialization required to identify specimens and the long processing times per traditional sample renders large scale ecosystem-wide traditional assessments expensive and time consuming ${ }^{15,45}$. In response there is a currently an ongoing rapid push to implement eDNA based riverine biodiversity assessment practices $21,26,30$, which forms the basis for this study.

Here, we assess seasonal patterns of biodiversity and functional diversity, using an experimental design which utilizes headwater sampling sites to associate local environmental conditions located within the same environmentally heterogeneous geographic region (e.g. catchment). We utilized a combined eDNA and traditional based biodiversity assessment approach to allow for direct comparison of historically supported ecological expectations from the traditional methods with molecular based eDNA methods. We investigated four main objectives and hypotheses. One, eDNA biodiversity will be greater and more diverse compared to traditional sampling, following previous experimental findings. Two, riverine macroinvertebrate biodiversity, specifically localized community richness, is expected to peak during spring and summer, when many stream macroinvertebrates are emerging as adults and reproducing, compared to fall and winter months when total biomass of many species has declined ${ }^{28,46}$. Three, utilizing the nested and turnover components of inter-community similarity (i.e. beta-diversity), we can expect high turnover within sites as community assembly changes over time, and high nestedness across environmental sites, attributed to environmental filtering of the localized sites. Alternatively, low 
nestedness could indicate a low effect of environmental filtering and a greater effect of stochastic or biotic factors influencing the localized community assemblies. Four, environmental filtering effects that are linked to habitat modification, such as agriculture or urbanized areas, are expected to negatively impact macroinvertebrate diversity, particularly Chironomidae, and Ephemeroptera, Plecoptera and Trichoptera (EPT) taxa ${ }^{47}$, indicating variable site-specific ecosystem health across the region. Functional diversity is also expected to be locally defined with functional feeding groups being predominately shredders in undisturbed forested sites, and collectors in the sites dominated by fine particulate input, including urbanized and moorland habitats ${ }^{48}$.

We found eDNA biodiversity to be a better descriptor of the total macroinvertebrate diversity across all sampling sites, with trends between the two methods showing general similarities. Community richness was greater in the spring and summer and lowest during the winter, as expected with the greatest change in community composition across seasons linked to changes in Chironomidae genera richness. Landuse, while showing distinct environmental differentiation, was not associated with local community richness. Additionally, spatio-temporal dynamics among communities were found to be predominately turnover driven, indicating strong seasonal or region-wide effects, whereas nestedness effects were mostly limited, suggesting weak localized environmental sorting of the communities. Lastly, functional diversity showed clear region-wide generalization of feeding functionality, suggesting biodiversity is driven by regionalbased bottom-up dynamics, which suggest biodiversity management should focus on regional over localized spatial extents.

\section{Results}

\section{Bioinformatics}

After stringent filtering and quality control, $12,592,362$ reads were obtained with an average of 74,954 ( \pm $31,050)$ reads per sample. Negative controls, while showing no bands on agarose gels post library preparation, generated 676 reads across all blanks $(\mathrm{N}=12)$. Of the negative control reads, 411 were unknown bacteria, 3 reads were associated with three genera of Rhodophyta (red algae), 2 reads were linked to unknown fungi, and 260 reads were linked to a single Dipteran ASV across four blanks. For downstream analyses, the Dipteran ASV was removed from subsequent analyses, whereas all other potential contaminants were not included as they were non-targeted. In total, 20,437 ASVs were identified. Average reads per site, after rarefaction was 75,871 $( \pm 37,670)$ with four sites having less than 10000 reads from four different sites across three different landuse types and two seasons. The average number of taxonomic assignments was 13,260 $( \pm 9,567)$. The average number of kicknet sampling specimens per site was 1,529 ( \pm 1555$)$. Mean site singletons were $9.86( \pm 6.67)$ for eDNA and $9.02( \pm$ 3.29) for kicknet sampling. Singletons were included in subsequent analyses given the robust use of 
sample replication used in the study design, whereby if a sequence was not observed in at least 2 of the 3 replicate samples the sequence was not included in the downstream analysis.

\section{Community dynamics}

All environmental variables and their associated summary statistics are presented in Table $1 \&$ Figure 2 . Overall, we observed 226 unique genera using the eDNA based approach and 83 genera using the traditional kick-netting approach (Table 2). On average, eDNA genera accounted for $78.2 \%$ of the unique observed diversity in a given site, with traditional methods accounting for $5.9 \%$ with an overlap between the two methods of $15.9 \%$ (Figure 3). Key differences between the methods were the higher number of genera observed using eDNA vs traditional methods for Chironomidae (75 vs 10), Oligochaeta (23 vs 2), Trichoptera (33 vs 24), Rotifera (8 vs 0), Coleoptera (20 vs 14) and Copepoda ( 5 vs 0 ) (Table 2). The full breakdown of genera per landuse type per sampling method can be found in Supplementary Table S1.

Genera richness derived from eDNA was significantly greater than traditional derived eDNA across season $(p<0.01)$ and landuse type $(p<0.001)$. There was a significant landuse $x$ method interaction effect $(p<0.01)$ and season $x$ method effect indicating non-covarying biodiversity dynamics between the two methods. Results for EPT also indicated non-covarying biodiversity dynamics with significant landuse $x$ method $(p<0.001)$, and method $x$ season $(p<0.001)$, whereas both methods showed significant differences across seasons and landuses. Chironomidae diversity also showed significant landuse $x$ method $(p<0.001)$ and method $x$ season $(p<0.001)$ interactions as well as significant effects of landuse and seasons on richness dynamics. Functional diversity showed significant landuse $x$ method $(p<0.001)$ and method $x$ season $(p<0.001)$ interactions, as well as seasonal $(p<0.001)$ (Table 3 \& Fig. 4$)$.

Change in community and functional diversity over time and space

Turnover was significantly greater than nestedness across landuse $(p<0.001)$ and season $(p<0.001)$ for genera derived from or traditional methods (Figure 5). The variation between turnover and nestedness did not differ across season $(p=0.66)$ or landuse $(p=0.082)$, but did differ significantly between methods $(p<0.001)$, with eDNA showing greater greater sensitivity to detect nestedness versus traditional methods (Figure 5). Positive and negative relationships with regards to landuse relate to the environmental gradient depicted in Fig S1 and described above. Changes in biodiversity over time, here turnover dominated, were directly related to the change in functionality over time (Fig. 6). For eDNA samples the 
increase in overall functionality was largely driven by the increase in number of genera from Diptera (all landuses), Coleoptera (Acid grasslands, Moorlands, Urban and Agriculture), Ephemeroptera (Forest), and Trichoptera (Forest and Moorlands). Transitioning into summer, acid grasslands and moorlands showed a loss of scraper and collector functionality stemming from losses in Plecoptera and Trichoptera genera. Losses of Plecoptera genera in forest sites resulted in a loss of scraper functionality, whereas gains in Plecoptera in the urban environments showed gains in collector functionality. Agricultural sites showed gains in scraper and gatherer function, due to some increases in Diptera and Trichoptera. Transitioning into fall indicated loss in functionality across landuse, driven by losses in Diptera (all landuses), Coleoptera (all landuses), Ephemeroptera (agricultural, moorland), and Trichoptera (urban, forest, agricultural). Winter was largely static, with the exception of gains in functionality for agricultural sites, which was driven by increased occurrence of Plecoptera and Trichoptera genera. Traditional samples indicated slight increases in functionality for agricultural and moorland landuses, primarily from increases in Plecoptera (agricultural, urban) and Coleoptera (moorland) genera. Summer increases in functionality for acid grasslands and moorlands were linked to increases in Trichoptera and Plecoptera in acid grasslands, and Plecoptera and Coleoptera in moorlands. Declines in fall gatherer function, in agricultural and forest landuses, were driven by losses in Trichoptera (agriculture sites) and Plecoptera (forest sites). Loss of functionality in winter for acid grassland, agricultural and moorlands was driven by losses in Trichoptera (acid grasslands), Plecoptera (acid grasslands, moorlands), Ephemeroptera (acid grasslands, agricultural, moorlands), and Coleoptera (acid grasslands).

\section{Discussion}

We show that eDNA based assessment offered a finer resolution of the spatial and temporal dynamics, making it a more efficient means to assess biodiversity dynamics. Additionally, biodiversity patterns derived from eDNA and traditional methods showed similar temporal trends in richness and functional diversity. Localized biodiversity richness showed no environmental filtering across the landuse types, whereas partitioning of beta-diversity showed clear differences in spatio-temporal dynamics. Specifically, regional environmental conditions were the main driver of biodiversity change and landuse effects were less pronounced. Importantly, we show here that eDNA based biodiversity assessments show meaningful spatial and temporal relationships, including increased ability to detect important indicator taxa, particularly Chironomidae and EPT taxa, which are difficult to directly sample for many of the locations or at different time points in the year. We also show the first example of eDNA derived functional temporal spatial dynamics, which provides clear management related information on how the ecosystem can be effectively managed.

As expected, biodiversity was greater during spring and summer months for both sampling methods. Genera richness dynamics differed between eDNA and traditional methods among landuse types, but not among seasons where eDNA derived diversity was consistently greater than traditional diversity. Importantly, we found greater eDNA derived diversity compared to traditional methods for all sites. While 
several studies have shown increased observable biodiversity using eDNA over traditional methods ${ }^{17,32}$, they have predominately focused on fish, whereas macroinvertebrate focused studies vary slightly with most showing greater ${ }^{30,49}$, but also some with lower eDNA diversity ${ }^{50}$, compared to traditional sampling. The disparity in macroinvertebrate diversity may stem from the increased difficulty in designing a suitable primer to capture the full range of diversity associated with macroinvertebrates, though see Leese et al. $2020^{51}$. Additionally, across landuse types, acid grasslands and moorland sites had greater eDNA diversity compared to agriculture, urban or forest sites. The results from eDNA monitoring were more in agreement with common expectation that unmodified landuse should hold greater biological diversity, particularly with regards to the higher diversity found in moorland and acid grassland sites, which were the least modified areas in the catchment. Traditional sampling, however, suggested greater biodiversity in agricultural and urban sites compared to moorlands or acid grasslands. The lower biodiversity observed with traditional methods metrics in the less disturbed sites is likely due, in part, to substrate types. The moorland and acid grassland sites are dominated by large boulders or loose sediment, which are not ideal substrates when performing traditional kicknet sampling methods, that perform better with gravel substrate (significant positive richness with increased gravel coverage $p=0.007$ ), and may lead to under sampling of the local taxa ${ }^{45}$. Previous studies have suggested eDNA transport from upstream communities can increase sampled biodiversity ${ }^{52,53}$. There is, however, no clear indication that the landscape or catchment surrounding these sites is any more diverse, as the moorland sites in particular are at higher elevation and more isolated compared to the other landuse sites. With upstream transported limited across the study system, the increased biodiversity is more likely an effect of eDNA versus traditional methodology than proposed eDNA ecology. As a recommendation, eDNA sampling is likely to be more beneficial overall compared to traditional sampling for detecting higher biological diversity, which has direct implications for detecting traditionally harder to identify biomonitoring groups such as Chironomidae or Diptera. Additionally, the use of eDNA is highly beneficial for sampling in traditionally difficult to sample locations, including non-traditional substrate types which could introduce bias when traditional, or bulk, sampling methodologies are used.

Environmental DNA biodiversity was greater for general biodiversity and all other subsets of biodiversity, including EPT, chironomids and functional diversity (Figures $3 \& 4$ ). The greatest increase in eDNA biodiversity resolution was in traditionally hard to identify groups, which would otherwise not be observable using taxonomic derived methods. Most revealingly, eDNA data more accurately depict Chironomidae life cycle patterns compared to traditional sampling. Specifically, seasonal variation in eDNA derived richness follows the expected larval emergence patterns, which increase over spring and summer, and steadily decline over fall and winter ${ }^{28}$, in contrast to traditional sampling which was unable to detect this seasonal shift, possibly due to the difficulty in traditionally observing Chironomidae. Likewise, EPT emergence was detectable via both eDNA and traditional sampling, as Ephemeroptera generally emerge during the spring whilst Trichoptera emerge at various times throughout the year. 
Spatio-temporal dynamics showed biodiversity was driven by regional turnover dynamics and less affected by localized environmental specialization or nestedness (Figures $5 \& 6$ ). Nestedness across sites was not significant with either method, suggesting that differences in biodiversity between sites was not due to localized environmental sorting, as per our initial expectations. The primary driver of observed heterogeneity in between site biodiversity was largely due to the seasonal turnover, likely driven by the high disturbance events historically occurring in the region of the study ${ }^{54}$, or due to very stronger effects of biotic interactions ${ }^{8}$. For the eDNA based methodology, there was a greater turnover observed in urban and forest sites, which was attributed to higher $\mathrm{pH}$ and lower moss and boulder coverage compared to other sites. Turnover in EPT and Chironomidae showed similar trends compared to overall turnover, whereby the differences in biodiversity between sites was significantly attributed to seasonal replacement of genera along the environmental gradient, which was predominately linked to $\mathrm{pH}$ and substrate type (Fig S1). Conversely, turnover was greater in moorland sites, linked to increased boulder and moss coverage. The disparity in the observed relationship between methods is likely driven largely by the methods themselves and the underlying richness values for each method, as mentioned above. Overall, both traditional and eDNA based turnover suggest seasonal turnover dominated differences in biodiversity, which could be attributed to adaptation (historical) of communities to regional conditions ${ }^{55}$. The biodiversity across the system is more likely a product of frequent founder and colonizing effects resulting from frequent disturbance patterns, and inability of the sites to establish long-term interacting communities ${ }^{56,57}$.

The functional diversity was largely dominated by collector feeders, indicating that the regional biodiversity assembly is driven by fine particulate organic matter (FPOM), which is also referred to as seston ${ }^{58,59}$. Two main factors contribute to the high FPOM driver across the study area. First, the widespread fecal input from animal agriculture that covers the entirety of the catchment. Additionally, for upland sites where agriculture is less prevalent, moorlands produce a high amount of FPOM ${ }^{60}$. The combined FPOM inputs from moorland and agricultural/urbanized environments creates a regional-wide FPOM system, thereby homogenizing the functional habitat of the region as a whole. Whereas the moorland effect is likely limited to certain headwater sites in this study, the quality difference in FPOM generated from agricultural vs moorland sources likely plays a role in the diversity differences seen between sites where collectors dominate on the whole ${ }^{43,58}$. Seasonal shifts in functional traits were observed with eDNA, but not with traditional methods. This is reflected in the ability of eDNA to detect more functional groups compared to traditional methods, particularly with regards to Diptera, including Chironomidae and Simuliidae (i.e. blackflies), which are important collector groups that are strongly affected by changes in temperature ${ }^{60}$. Likewise, eDNA functional assessment indicates a change in grazer functionality with season, closely following expectations of periphyton availability, which is a key driver of grazer activity ${ }^{61}$. The homogeneity in functional diversity between the landuse sites for both 
eDNA and traditional based methods further indicated that environmental filtering was not the primary driver of biodiversity difference between sites. A key take home message from assessing functional diversity in the study, over simply relying on variation in richness, is that these findings point to a clear management strategy to increase diversity across the system. Specifically, regional biodiversity would benefit by increasing the habitat for collector functional groups through improved management of local broadleaf forest, and agricultural practices to increase coarse feeding material at key head water sites, which would increase the overall ecosystem stability of the region by increasing environmental heterogeneity.

A wider implication arising from this study is the suggestion that eDNA can disclose a much greater resolution of diversity compared to traditional approaches and can enable multiple levels of analyses from a single data set. The benefit of comparing traditional findings with eDNA based analyses, which can be analyzed using standardized approaches, is immensely valuable and will help avoid unintended biases introduced from cross study traditional protocols. Overall, our findings show that eDNA is a more effective survey method to sample macroinvertebrates and provides clearer indications of the seasonal and environmental effects on multiple levels of diversity compared to traditional methods. Additionally, we provide a key assessment of regional biodiversity dynamics, which are currently underrepresented in the literature. Specifically, we show that the increased resolution of eDNA based biodiversity assessment effectively separates spatio-temporal and localized biodiversity dynamics, which here shows the importance of regional over localized management strategies. Determining such regional drivers allows for effective biological management, whereby flood control, versus altering current landuse practices, is more likely to have a greater impact on biodiversity in disturbance driven sites. Finally, by utilizing functional diversity assessment we show a clear reason for why community composition has arisen. Empowered by eDNA metabarcoding and appropriate ecological synthesis, we therefore provide a more valuable means to describing biodiversity than simply counting unique individual units with no link to what the numbers mean at ecological and ecosystem scale.

\section{Methods}

Study Area

The Conwy Catchment is a $678 \mathrm{~km}^{2}$ river drainage in north Wales that encompasses a wide range of habitats including forest, moorland, agriculture, light urbanization, and acid grasslands (Fig. 1). The area experiences rapid climatic shifts, particularly during winter months due to its mountainous terrain and porous rock foundations, which facilitates flash flooding, making it susceptible to periodic disturbance ${ }^{54}$. The Conwy Catchment area exhibits four distinct seasons that correspond to the expected life cycles of EPT and Chironomidae larval emergences throughout the year. 


\section{Sampling}

Fourteen headwater sites across 5 landuse types (acid grassland, agriculture, forest, urban, moorland) were sampled once per season (spring, summer, fall, winter), during 2017 (5 landuse types x14 sites x4 seasons). Headwater sites were selected to ensure local landuse types were not influenced by other landuse type via downstream transport ${ }^{62,63}$. In total 168 eDNA samples and 56 traditional kick-net samples were taken over the course of the study. Sampling for each season occurred over two consecutive days. For all sampling events, streams were sampled for both eDNA and macroinvertebrate community composition during the same day. Water samples for eDNA analysis $(1 \mathrm{~L})$ were collected in triplicates from each stream with plastic bottles that had been cleaned prior using a $10 \%$ bleach solution (soaked for 1 hour). These were then filtered through $0.22 \mu \mathrm{m}$ SterivexTM filter units (EMD Millipore Corporation, Billerica, USA) using a Geopump TM Series II peristaltic pump (Geotech, Denver, USA). As filters would occasionally experience reduced filtration efficiency for different sites, or seasons, due to stream sediment loading, we would continue to run the pump for each sample until at least $500 \mathrm{ml}$ was filtered, to avoid potential downstream variation in sampling ${ }^{64}$, which we previously showed was not an issue in this experimental setup ${ }^{53}$. The filters were immediately preserved in $500 \mu$ ATL lysis buffer (Qiagen, Venlo, The Netherlands) and stored in coolers during same-day transit to the laboratory, then stored at $0{ }^{\circ} \mathrm{C}$, for further processing. Macroinvertebrate communities were sampled using a standardized 3-minute kick sampling protocol, with a $500 \mu \mathrm{m}$ mesh gauge kick/hand net. Kicknet sampling occurred after eDNA sampling to ensure disturbance of the site from kicknetting would not influence the eDNA signal. Both bank margins and riffle habitats were sampled during this timed sampling period. Macroinvertebrates were preserved in absolute ethanol (99.8\%; VWR International, Lutterworth, UK) on collection. Upon return to the laboratory the macroinvertebrates were cleared of other collected material and identified to the lowest practical taxonomic per protocol ${ }^{65}$. Environmental (abiotic) data including pH, conductivity, depth, moss coverage, algal coverage, plant coverage boulder coverage, gravel coverage and sand coverage, were collected for each site following UK Environment Agency site assessment protocols ${ }^{65}$. Three field blanks consisting of deionized water were prepared in Nalgene sampling bottles and were kept with the other sampling gear throughout each sampling event. For each seasonal sampling event we incorporated three field blanks into the sampling process, processing one blank every $4^{\text {th }}$ sampling site, resulting in a total of 12 blanks for the study. Field blanks were $1 \mathrm{~L}$ in volume and treated the same as standard samples.

Extraction and Sequencing 
We followed unidirectional lab practices from field, to extraction to library preparation by using designated extraction (PCR free) and library preparation rooms. DNA was extracted from the filters using a modified QIAGEN DNA blood and tissue extraction protocol ${ }^{66}$. In short, $70 \mu$ l proteinase $\mathrm{K}$ was added directly to the filters and incubated at $58{ }^{\circ} \mathrm{C}$ overnight in a rotating hybridization chamber. Then, the lysate was extracted and the full volume was filtered through a spin column tube, after which point the standard extraction protocol was continued. Extracts (final volume $50 \mu \mathrm{l}$ ) were then cleaned for impurities using QIAGEN Power Clean kit and frozen at $-20^{\circ} \mathrm{C}$ for subsequent analyses. Sequencing libraries were created using a two-step protocol (see Bista et al. 2017), using matching dual end index tags (IDT) and the following $\mathrm{COI}$ gene region primers for the first round of PCR (PCR1): m1COlintF (5'-

GGWACWGGWTGAACWGTWTAYCCYCC-3') and jgHCO2198 (5'-TAIACYTCIGGRTGICCRAARAAYCA-3') ${ }^{67}$. Libraries were created at Bangor with the assistance of a Gilson pipette max liquid handler before being shipped to University of Birmingham's Genomic sequencing facility for quality control and sequencing. Round 1 amplification (PCR1) with the COI primers was performed in triplicates, which were then cleaned for primer dimers using magnetic beads (Beckman coulter), pooled and index labeled during Round 2 PCR step (PCR2), which were cleaned again using magnetic beads. Unique dual paired end-indices were designed and purchased from Integrated DNA Technologies, to complement the Illumina P5/P7 sequence adapters. PCR1 utilized Thermo Scientific's Ampli-gold mastermix due to the high number of inosine in the COI primer pair, and for PCR2 we utilized New England Biolab's Q5 mastermix. All PCR1 and PCR2 reactions were run in $25 \mu \mathrm{L}$ volumes. PCR1 amplicons were generated using a reaction mix of $12.5 \mu \mathrm{L}$ mastermix, $2 \mu \mathrm{L}$ DNA template, $1 \mu \mathrm{L}$ of each primer and $8 \mu \mathrm{L}$ nuclease free water and amplified using an initial $95^{\circ} \mathrm{C}$ for 5 min then 25 cycles of $95^{\circ} \mathrm{C}$ for $30 \mathrm{~s}, 54^{\circ} \mathrm{C}$ for $30 \mathrm{~s}$ and $72{ }^{\circ} \mathrm{C}$ for $60 \mathrm{~s}$ followed by a 72 ${ }^{\circ} \mathrm{C}$ final annealing for $10 \mathrm{~min}$. PCR2 amplicons were generated using a reaction mix of $12.5 \mu \mathrm{L}$ mastermix, $2 \mu \mathrm{L}$ DNA template, $1 \mu \mathrm{L}$ of each primer and $8 \mu \mathrm{L}$ nuclease free water and amplified using an initial $98^{\circ} \mathrm{C}$ for $30 \mathrm{~s}$ then 15 cycles of $98^{\circ} \mathrm{C}$ for $10 \mathrm{~s}, 55^{\circ} \mathrm{C}$ for $30 \mathrm{~s}$ and $72{ }^{\circ} \mathrm{C}$ for $30 \mathrm{~s}$ followed by a $72{ }^{\circ} \mathrm{C}$ final annealing for 10 min. The, PCR2 amplicons were purified using High Prep PCR magnetic beads (Auto Q Biosciences) and quantified using a 200 pro plate reader (TECAN) with the Qubit dsDNA HS kit (Invitrogen). The final amplicons were pooled in equimolar quantities (at a final concentration of 12 pmol) using a Biomek FXp liquid handling robot (Beckman Coulter). Pool molarity was confirmed using a HS D1000 Tapestation ScreenTape (Agilent). Sequencing was performed on an Illumina HiSeq platform $250 \mathrm{bp}$ Paired-End, with an intended coverage of 100,000 reads per sample.

\section{Bioinformatics}

Bioinformatic processing up to taxonomic assignment was performed by University of Birmingham. In short, per base quality trimming was performed on demultiplexed reads using SolexaQA++ v.3.1.7.1 (Cox, Peterson, \& Biggs, 2010) and paired end reads were merged using Flash v.1.2.11 ${ }^{68}$, with default parameters. Primer sequences were removed with TagCleaner v.0.16 ${ }^{69}$ allowing up to 3 mismatches per 
primer sequence. Only sequences with both forward and reverse primers were retained for further analyses. Amplicon sequence variants (ASVs) were obtained via Usearch at $97 \%$ similarity threshold, and denoising with the -unoise3 algorithm. Chimeras were removed as part of the -unoise3 algorithm ${ }^{70}$. Taxonomy to the genus level was assigned to representative ASV with BLAST against ASVs using the non-redundant nucleotide database of NCBI, using the default settings ${ }^{71}$.

\section{Metacommunity analyses}

All statistical analyses were performed using $\mathrm{R}$ version 3.6.1 ${ }^{72}$. Sequence reads were rarified for each set of replicates to the lowest replicate level. Mean number of reads for each ASV were calculated across the sample replicates before being matched to their taxonomic identifier. ASVs that were not identifiable to the genus level, or to a functional group (below), were not included in subsequent analyses. Genera richness was calculated as the number of unique genera per site. We further divided richness into unique EPT genera for EPT richness, and Chironomidae richness as the number of unique Chironomidae genera. Functional richness was calculated as the partition of unique functional groups per sample, following the partition of functional groups in Moog (2017). In short, Moog (2017) provides a catalogue of 3296 metazoa species that form the basis of ecological status assessment for many European environmental agencies. The functional scores are assigned to each taxa based on a ten point partitioning to reflect the variation in functionality within taxa, meaning the functional scores is a score of the function and not simply a reassignment of the taxonomic identification. These groups reflect the functional feeding groups, divided into 8 categories, including; grazer/scrapers, xylophagous, shredders, gatherers/collectors, active filter feeders, passive filter feeders, predators and other. We refined these groups to shredders, grazers, and collectors whereby collectors were the summation of gather/collectors and filter feeding groups to simplify the functional groups to those used across wider studies. To assess community dynamics between sites we calculated the nestedness and turnover components of betadiversity following Baselga (2010) ${ }^{14}$, whereby beta-diversity was calculated as $\beta$ sor (1), Turnover as $\beta$ sim (2) and $\beta$ nes as $\beta$ sorminus $\beta \operatorname{sim}(3)^{14}$. All mathematical formula follow the nomenclature of Baselga (2010), with a being the number of genera common to both sites, $b$ is the number of genera occurring in the first site but not the second and $c$ is the number of genera occurring in the second site but not the first. 
(1) $\beta$ sor $=\frac{b+c}{2 a+b+c}$

(2) $\beta \operatorname{sim}=\frac{\min (b, c)}{a+\min (b, c)}$

\section{(3) $\beta$ nes $=\beta$ sor $-\beta$ sim}

We used generalized least squares (gls), as implemented using the gls function in the nlme package ${ }^{73}$, to assess the statistical relationships between (1) community, (2) EPT, (3) Chironomidae, and (4) functional richness (each as a separate response variable and independent statistical test) and all two-way interactions of the explanatory variables, including sampling method (eDNA or traditional), season (spring, summer, fall and winter) and landuse gradient (see below for description). Generalized least squares is an extension of linear regression that allows for variance structuring of variables to account for suspected correlation between residuals. Here, we specifically used the gls framework to account for potential spatial autocorrelation between sites by included a variance structure using the distance matrix for the sampling sites ${ }^{73}$. We further used gls to assess the statistical relationships between nestedness and turnover between communities against a set of explanatory variables, including the landuse gradient, sampling method, and season, including all possible two-way interactions. Backward model selection was performed to find the most parsimonious model using Akaike information criterion (AIC) to determine the best model fit ${ }^{74}$. Model assumptions, including normality and heteroscedasticity using model diagnostic plots were implemented in R. The landscape gradient was calculated as the first principal component of a PCA derived from non-covarying environmental variables (normalized and centered prior to PCA analysis), where non-covariance was assessed via visualization of the pairwise correlation between all measured environmental variables (Supplementary Figure 1) (Borcard, Gillet, \& Legendre, 2011). The first axes of the PCA, which was used as the derived environmental gradient, accounted for $67.47 \%$ of the observed variation with environmental loadings consisting of $\mathrm{pH}(0.027)$, moss coverage $(-0.449)$, depth $(-0.297)$ and boulder coverage $(-0.842)$.

\section{Data availability}

Data including amplicon sequence data, ASV matrices and environmental data associated with the manuscript will be deposited on figshare.

Code availability 
The analyses utilized standard language coding commands for the bioinformatics and data analyses as described in the methods.

\section{References}

1. Díaz, S. et al. Summary for policymakers of the global assessment report on biodiversity and ecosystem services of the Intergovernmental Science-Policy Platform on Biodiversity and Ecosystem Services. Nat. Resour. Environ. 34, (2020).

2. Laureto, L. M. O., Cianciaruso, M. V. \& Samia, D. S. M. Functional diversity: an overview of its history and applicability. Nat. Conserv. 13, 112-116 (2015).

3. Gilbey, J. et al. Life in a drop: Sampling environmental DNA for marine fishery management and ecosystem monitoring. Mar. Policy 124, 104331 (2021).

4. de Chazal, J. \& Rounsevell, M. D. A. Land-use and climate change within assessments of biodiversity change: A review. Glob. Environ. Chang. 19, 306-315 (2009).

5. Benayas, J. M. R., Newton, A. C., Diaz, A. \& Bullock, J. M. Enhancement of Biodiversity and Ecosystem Services by Ecological Restoration: A Meta-Analysis. Science (80-. ). 325, 1121-1124 (2009).

6. Ovaskainen, O. et al. How to make more out of community data? A conceptual framework and its implementation as models and software. Ecol. Lett. 20, 561-576 (2017).

7. Leibold, M. A. \& Miller, T. E. From metapopulations to metacommunities. in Ecology, genetics and evolution of metapopulations (eds. Hanski, I. \& Gaggiotti, O. E.) 133-150 (Elsevier Academic Pres, 2004).

8. Kraft, N. J. B. et al. Community assembly, coexistence and the environmental filtering metaphor. Funct. Ecol. 29, 592-599 (2015).

9. Donohue, I. et al. Navigating the complexity of ecological stability. Ecol. Lett. 19, 1172-1185 (2016).

10. Flynn, D. F. B., Mirotchnick, N., Jain, M., Palmer, M. I. \& Naeem, S. Functional and phylogenetic diversity as predictors of biodiversity-ecosystem-function relationships. Ecology 92, 1573-1581 (2011).

11. Cardinale, B. J. et al. The functional role of producer diversity in ecosystems. Am. J. Bot. 98, 572592 (2011).

12. Young, R. G. \& Collier, K. J. Contrasting responses to catchment modification among a range of functional and structural indicators of river ecosystem health. Freshw. Biol. 54, 2155-2170 (2009).

13. Koleff, P., Gaston, K. J. \& Lennon, J. J. Measuring beta diversity for presence-absence data. J. Anim. Ecol. 72, 367-382 (2003).

14. Baselga, A. Partitioning the turnover and nestedness components of beta diversity. Glob. Ecol. Biogeogr. 19, 134-143 (2010).

15. de Oliveira, S. S., Ortega, J. C. G., Ribas, L. G. dos S., Lopes, V. G. \& Bini, L. M. Higher taxa are sufficient to represent biodiversity patterns. Ecol. Indic. 111, 105994 (2020). 
16. Seymour, M. et al. Nestedness and turnover of riverine species and functional diversity using eDNA and traditional approaches. Res. Sq. (2020) doi:10.21203/rs.3.rs-82612/v2.

17. Boivin-Delisle, D. et al. Using environmental DNA for biomonitoring of freshwater fish communities: Comparison with established gillnet surveys in a boreal hydroelectric impoundment. Environ. DNA n/a, (2020).

18. Sepulveda, A. J., Nelson, N. M., Jerde, C. L. \& Luikart, G. Are Environmental DNA Methods Ready for Aquatic Invasive Species Management? Trends Ecol. Evol. 35, 668-678 (2020).

19. Beng, K. C. \& Corlett, R. T. Applications of environmental DNA (eDNA) in ecology and conservation: opportunities, challenges and prospects. Biodivers. Conserv. 29, 2089-2121 (2020).

20. Bohmann, K. et al. Environmental DNA for wildlife biology and biodiversity monitoring. Trends Ecol. Evol. 29, 358-367 (2014).

21. Seymour, M. Rapid progression and future of environmental DNA research. Commun. Biol. 2, 80 (2019).

22. Jo, T., Arimoto, M., Murakami, H., Masuda, R. \& Minamoto, T. Particle Size Distribution of Environmental DNA from the Nuclei of Marine Fish. Environ. Sci. Technol. 53, 9947-9956 (2019).

23. Moushomi, R., Wilgar, G., Carvalho, G., Creer, S. \& Seymour, M. Environmental DNA size sorting and degradation experiment indicates the state of Daphnia magna mitochondrial and nuclear eDNA is subcellular. Sci. Rep. 9, 12500 (2019).

24. Sassoubre, L. M., Yamahara, K. M., Gardner, L. D., Block, B. A. \& Boehm, A. B. Quantification of Environmental DNA (eDNA) Shedding and Decay Rates for Three Marine Fish. Environ. Sci. Technol. 50, 10456-10464 (2016).

25. Turner, C. R. et al. Particle size distribution and optimal capture of aqueous macrobial eDNA. Methods Ecol. Evol. 5, 676-684 (2014).

26. Seymour, M. et al. Acidity promotes degradation of multi-species environmental DNA in lotic mesocosms. Commun. Biol. 1, 4 (2018).

27. Collins, R. A. et al. Persistence of environmental DNA in marine systems. Commun. Biol. 1, 185 (2018).

28. Bista, I. et al. Annual time-series analysis of aqueous eDNA reveals ecologically relevant dynamics of lake ecosystem biodiversity. Nat. Commun. 8, (2017).

29. Sales, N. G. et al. Fishing for mammals: Landscape-level monitoring of terrestrial and semi-aquatic communities using eDNA from riverine systems. J. Appl. Ecol. 57, 707-716 (2020).

30. Seymour, M. et al. Executing multi-taxa eDNA ecological assessment via traditional metrics and interactive networks. Sci. Total Environ. 729, 138801 (2020).

31. Riascos, L. et al. DNA-based monitoring of the alien invasive North American crayfish Procambarus clarkii in Andean lakes (Ecuador). Limnologica 70, 20-25 (2018).

32. Hänfling, B. et al. Environmental DNA metabarcoding of lake fish communities reflects long-term data from established survey methods. Mol. Ecol. 25, 3101-3119 (2016). 
33. Crookes, S. et al. Monitoring the silver carp invasion in Africa: a case study using environmental DNA (eDNA) in dangerous watersheds. NeoBiota 56, 31-47 (2020).

34. Sigsgaard, E. E. et al. Using vertebrate environmental DNA from seawater in biomonitoring of marine habitats. Conserv. Biol. 34, 697-710 (2020).

35. Stat, M. et al. Ecosystem biomonitoring with eDNA: metabarcoding across the tree of life in a tropical marine environment. Sci. Rep. 7, 12240 (2017).

36. Valdez-Moreno, M. et al. Using eDNA to biomonitor the fish community in a tropical oligotrophic lake. PLoS One 14, e0215505-e0215505 (2019).

37. Vannote, R. L., Minshall, G. W., Cummins, K. W., Sedell, J. R. \& Cushing, C. E. The River Continuum Concept. Can. J. Fish. Aquat. Sci. 37, 130-137 (1980).

38. Seymour, M., Fronhofer, E. A. \& Altermatt, F. Dendritic network structure and dispersal affect temporal dynamics of diversity and species persistence. Oikos 124, 908-916 (2015).

39. Seymour, M., Deiner, K. \& Altermatt, F. Scale and scope matter when explaining varying patterns of community diversity in riverine metacommunities. Basic Appl. Ecol. 17, 134-144 (2016).

40. Altermatt, F., Seymour, M. \& Martinez, N. River network properties shape a-diversity and community similarity patterns of aquatic insect communities across major drainage basins. J. Biogeogr. 40, (2013).

41. Eyre, M. D., Pilkington, J. G., McBlane, R. P. \& Rushton, S. P. Macroinvertebrate species and assemblages in the headwater streams of the River Tyne, northern England in relation to land cover and other environmental variables. Hydrobiologia 544, 229-240 (2005).

42. Haase, P., Pauls, S. U., Schindehütte, K. \& Sundermann, A. First audit of macroinvertebrate samples from an EU Water Framework Directive monitoring program: human error greatly lowers precision of assessment results. J. North Am. Benthol. Soc. 29, 1279-1291 (2010).

43. Miserendino, M. L. \& Masi, C. I. The effects of land use on environmental features and functional organization of macroinvertebrate communities in Patagonian low order streams. Ecol. Indic. 10, 311-319 (2010).

44. Wallace, J. B. \& Webster, J. R. The Role of Macroinvertebrates in Stream Ecosystem Function. Annu. Rev. Entomol. 41, 115-139 (1996).

45. Barbour, M. T., Gerritsen, J., Snyder, B. D. \& Stribling, J. B. Rapid bioassessment protocols for use in streams and wadeable rivers: periphyton, benthic macroinvertebrates and fish. vol. 339 (US Environmental Protection Agency, Office of Water Washington, DC, 1999).

46. Milner, A. M., Robertson, A. L., Monaghan, K. A., Veal, A. J. \& Flory, E. A. Colonization and development of an Alaskan stream community over 28 years. Front. Ecol. Environ. 6, 413-419 (2008).

47. Álvarez-Cabria, M., Barquín, J. \& Antonio Juanes, J. Spatial and seasonal variability of macroinvertebrate metrics: Do macroinvertebrate communities track river health? Ecol. Indic. 10, 370-379 (2010). 
48. McGoff, E., Solimini, A. G., Pusch, M. T., Jurca, T. \& Sandin, L. Does lake habitat alteration and landuse pressure homogenize European littoral macroinvertebrate communities? J. Appl. Ecol. 50, 10101018 (2013).

49. Macher, J.-N. et al. Comparison of environmental DNA and bulk-sample metabarcoding using highly degenerate cytochrome c oxidase I primers. Mol. Ecol. Resour. 18, 1456-1468 (2018).

50. Pereira-da-Conceicoa, L. et al. Metabarcoding unsorted kick-samples facilitates macroinvertebratebased biomonitoring with increased taxonomic resolution, while outperforming environmental DNA. bioRxiv 792333 (2019) doi:10.1101/792333.

51. Leese, F. et al. Improved freshwater macroinvertebrate detection from environmental DNA through minimized nontarget amplification. Environ. DNA n/a, (2020).

52. Carraro, L., Hartikainen, H., Jokela, J., Bertuzzo, E. \& Rinaldo, A. Estimating species distribution and abundance in river networks using environmental DNA. Proc. Natl. Acad. Sci. 115, 11724 LP - 11729 (2018).

53. Seymour, M. et al. Acidity promotes degradation of multi-species environmental DNA in lotic mesocosms. Commun. Biol. 1, 4 (2018).

54. Bussi, G. et al. Climate and land-use change impact on faecal indicator bacteria in a temperate maritime catchment (the River Conwy, Wales). J. Hydrol. 553, 248-261 (2017).

55. Ricklefs, R. E. Community diversity: relative roles of local and regional processes. Science (80- ). 235, 167-171 (1987).

56. Harvey, E., Gounand, I., Fronhofer, E. A. \& Altermatt, F. Disturbance reverses classic biodiversity predictions in river-like landscapes. Proc. R. Soc. B Biol. Sci. 285, 20182441 (2018).

57. Townsend, C. R., Scarsbrook, M. R. \& Dolédec, S. The intermediate disturbance hypothesis, refugia, and biodiversity in streams. Limnol. Oceanogr. 42, 938-949 (1997).

58. Cummins, K. W. \& Klug, M. J. Feeding Ecology of Stream Invertebrates. Annu. Rev. Ecol. Syst. 10, 147-172 (1979).

59. Wallace, J., Hutchens John, J. \& Grubaugh, J. Chapter 12. Transport and Storage of FPOM. in Methods in Stream Ecology 249-271 (2007). doi:10.1016/B978-012332908-0.50014-0.

60. Erman, D. C. \& Chouteau, W. C. Fine Particulate Organic Carbon Output from Fens and Its Effect on Benthic Macroinvertebrates. Oikos 32, 409-415 (1979).

61. Hart, D. D. \& Robinson, C. T. Resource Limitation in a Stream Community: Phosphorus Enrichment Effects on Periphyton and Grazers. Ecology 71, 1494-1502 (1990).

62. Carraro, L., Mächler, E., Wüthrich, R. \& Altermatt, F. Environmental DNA allows upscaling spatial patterns of biodiversity in freshwater ecosystems. Nat. Commun. 11, 3585 (2020).

63. Finn, D. S., Bonada, N., Múrria, C. \& Hughes, J. M. Small but mighty: headwaters are vital to stream network biodiversity at two levels of organization. J. North Am. Benthol. Soc. 30, 963-980 (2011).

64. Mächler, E., Deiner, K., Spahn, F. \& Altermatt, F. Fishing in the Water: Effect of Sampled Water Volume on Environmental DNA-Based Detection of Macroinvertebrates. Environ. Sci. Technol. 50, 305-312 
(2016).

65. Agency, E. River Habitat Survey in Britain and Ireland: Field Survey Guidance Manual: 2003 Version. (Forest Research, 2003).

66. Spens, J. et al. Comparison of capture and storage methods for aqueous macrobial eDNA using an optimized extraction protocol: advantage of enclosed filter. Methods Ecol. Evol. 8, 635-645 (2017).

67. Leray, M. et al. A new versatile primer set targeting a short fragment of the mitochondrial COI region for metabarcoding metazoan diversity: application for characterizing coral reef fish gut contents. Front. Zool. 10, 34 (2013).

68. Magoč, T. \& Salzberg, S. L. FLASH: fast length adjustment of short reads to improve genome assemblies. Bioinformatics 27, 2957-2963 (2011).

69. Schmieder, R., Lim, Y. W., Rohwer, F. \& Edwards, R. TagCleaner: Identification and removal of tag sequences from genomic and metagenomic datasets. BMC Bioinformatics 11, 341 (2010).

70. Edgar, R. C. UNOISE2: improved error-correction for Illumina $16 \mathrm{~S}$ and ITS amplicon sequencing. bioRxiv 81257 (2016) doi:10.1101/081257.

71. Coordinators, N. R. Database resources of the National Center for Biotechnology Information. Nucleic Acids Res. 44, D7-D19 (2016).

72. R Core Team. R: A Language and Environment for Statistical Computing. (2019).

73. Pinheiro, J. C. \& Bates, D. M. Mixed-effects models in S and S-plus. (Springer, 2000).

74. Borcard, D., Gillet, F. \& Legendre, P. Numerical Ecology with R. (Springer, 2011).

\section{Declarations}

Acknowledgements

Helen C. Rees and two anonymous reviewers for reviewing the manuscript. Centre for Ecology and Hydrology for field surveying, sampling assistance and macroinvertebrate identification. Genomics Center at University of Birmingham for sequencing and initial bioinformatics services. The project was supported by a Natural Environment Research Council grant (parent-grant NE/N006216/1; sub-grants NE/N005724/1 and NE/N00576/1).

\section{Author Contributions}

Designed Research: MS, FE, BC; Performed Research: MS, PS, FE; IB; Analyzed Data: MS; Wrote Paper: MS; Contributed critically to initial drafts of the paper: FE, BC, IB, GRC, MdB. All authors, including SC, FB and HCG commented on the final version of the manuscript.

\section{Tables}


Table 1. Environmental site variables (first column) with the associated mean, standard deviation, min and max across sampling sites.

\begin{tabular}{|llllll|}
\hline & Units & Mean & SD & Min & Max \\
\hline $\mathrm{pH}$ & & 6.87 & 0.67 & 5.17 & 7.55 \\
\hline Conductivity & $\mu \mathrm{S} / \mathrm{cm}$ & 92.21 & 69.98 & 25.50 & 252.50 \\
\hline Depth & $\mathrm{cm}$ & 17.87 & 8.84 & 6.33 & 37.00 \\
\hline Moss & $\%$ & 8.61 & 9.46 & 0.25 & 31.25 \\
\hline Algae & $\%$ & 2.32 & 4.31 & 0.00 & 15.00 \\
\hline Plant & $\%$ & 1.16 & 1.26 & 0.00 & 3.75 \\
\hline Boulder & $\%$ & 51.02 & 15.31 & 18.33 & 73.00 \\
\hline Gravel & $\%$ & 42.69 & 12.12 & 26.25 & 65.75 \\
\hline Sand & $\%$ & 6.06 & 4.28 & 0.75 & 18.33 \\
\hline
\end{tabular}

Table 2. Number of genera recorded per sampling method by higher taxa group. 


\begin{tabular}{|c|c|c|}
\hline \multirow[t]{2}{*}{ Higher Taxa } & \multicolumn{2}{|c|}{ Number of Genera } \\
\hline & eDNA & Traditional \\
\hline Amphipoda & 1 & 1 \\
\hline Chilopoda & 1 & 0 \\
\hline Chironomid & 75 & 10 \\
\hline Cladocera & 4 & 1 \\
\hline Coelenterata & 2 & 0 \\
\hline Coleoptera & 20 & 14 \\
\hline Collembola & 3 & 0 \\
\hline Copepoda & 5 & 0 \\
\hline Ephemeroptera & 11 & 9 \\
\hline Gastropoda & 3 & 3 \\
\hline Hemiptera & 4 & 1 \\
\hline Hirudinea & 4 & 3 \\
\hline Hydracarina & 1 & 0 \\
\hline Isopoda & 2 & 1 \\
\hline Lepidoptera & 1 & 0 \\
\hline Megaloptera & 1 & 1 \\
\hline Microturbellaria & 1 & 0 \\
\hline Nematoda & 1 & 0 \\
\hline Neuroptera & 1 & 0 \\
\hline Odonata & 4 & 1 \\
\hline Oligochaeta & 23 & 2 \\
\hline Ostracoda & 2 & 0 \\
\hline Plecoptera & 13 & 12 \\
\hline Porifera & 1 & 0 \\
\hline Rotifera & 8 & 0 \\
\hline Tardigrada & 1 & 0 \\
\hline Trichoptera & 33 & 24 \\
\hline
\end{tabular}

Page 22/30 
Table 3. Richness generalized least squares (GLS) statistics for the different levels of richness used in the study including genera, Chironomidae, EPT and functional richness, tested against the set of explanatory variables including landuse type, method (eDNA/traditional), season and the possible two-way interactions. The model includes a variance pairwise distance variance structure to account for spatial autocorrelation. Models shown are the most parsimonious models with the associated model metrics, including degrees of freedom (DF), f-value and $p$-value, given for each set of response and explanatory variables. P-values in bold indicate significant effects.

\begin{tabular}{|c|c|c|c|c|}
\hline Response & Explanatory & Df & F value & $\mathrm{p}$-value \\
\hline \multirow[t]{5}{*}{ Genera } & Landuse & 1 & 5.81 & 0.018 \\
\hline & Season & 3 & 5.42 & 0.002 \\
\hline & Method & 1 & 184.00 & $<0.001$ \\
\hline & Landuse:Method & 1 & 31.06 & $<0.001$ \\
\hline & Season:Method & 3 & 4.09 & 0.009 \\
\hline \multirow[t]{4}{*}{ Chironomidae } & Landuse & 1 & 3.51 & 0.064 \\
\hline & Season & 3 & 5.79 & 0.001 \\
\hline & Method & 1 & 38.29 & $<0.001$ \\
\hline & Landuse:Method & 1 & 39.43 & $<0.001$ \\
\hline \multirow[t]{5}{*}{ EPT } & Landuse & 1 & 8.60 & 0.004 \\
\hline & Season & 3 & 19.98 & $<0.001$ \\
\hline & Method & 1 & 422.00 & $<0.001$ \\
\hline & Landuse:Method & 1 & 13.56 & 0.000 \\
\hline & Season:Method & 3 & 17.04 & $<0.001$ \\
\hline \multirow[t]{7}{*}{ Function } & Landuse & 1 & 10.40 & 0.001 \\
\hline & Season & 3 & 12.35 & $<0.001$ \\
\hline & Method & 1 & 431.53 & $<0.001$ \\
\hline & Group & 2 & 127.09 & $<0.001$ \\
\hline & Landuse:Method & 1 & 104.27 & $<0.001$ \\
\hline & Season:Method & 3 & 9.15 & $<0.001$ \\
\hline & Method:Group & 2 & 50.18 & $<0.001$ \\
\hline
\end{tabular}




\section{Figures}

Legend

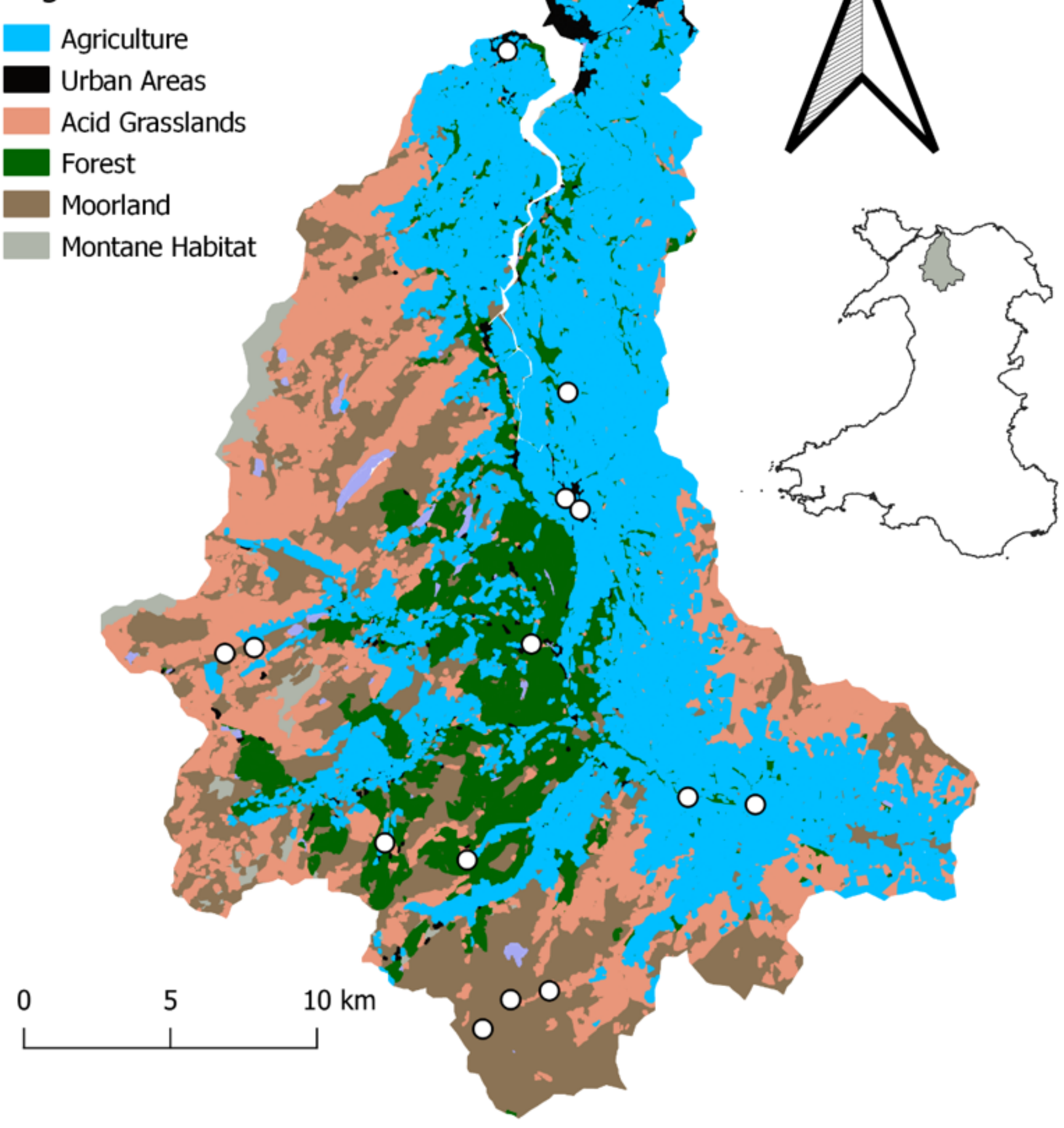

\section{Figure 1}

Map of the study area (Conwy Catchment, North Wales). Colors) colors correspond to different landuse types, including agriculture (blue), bog/moorland (brown), acid grassland (pink), forested (green), and urban areas (black). White circles indicate sampling locations. 

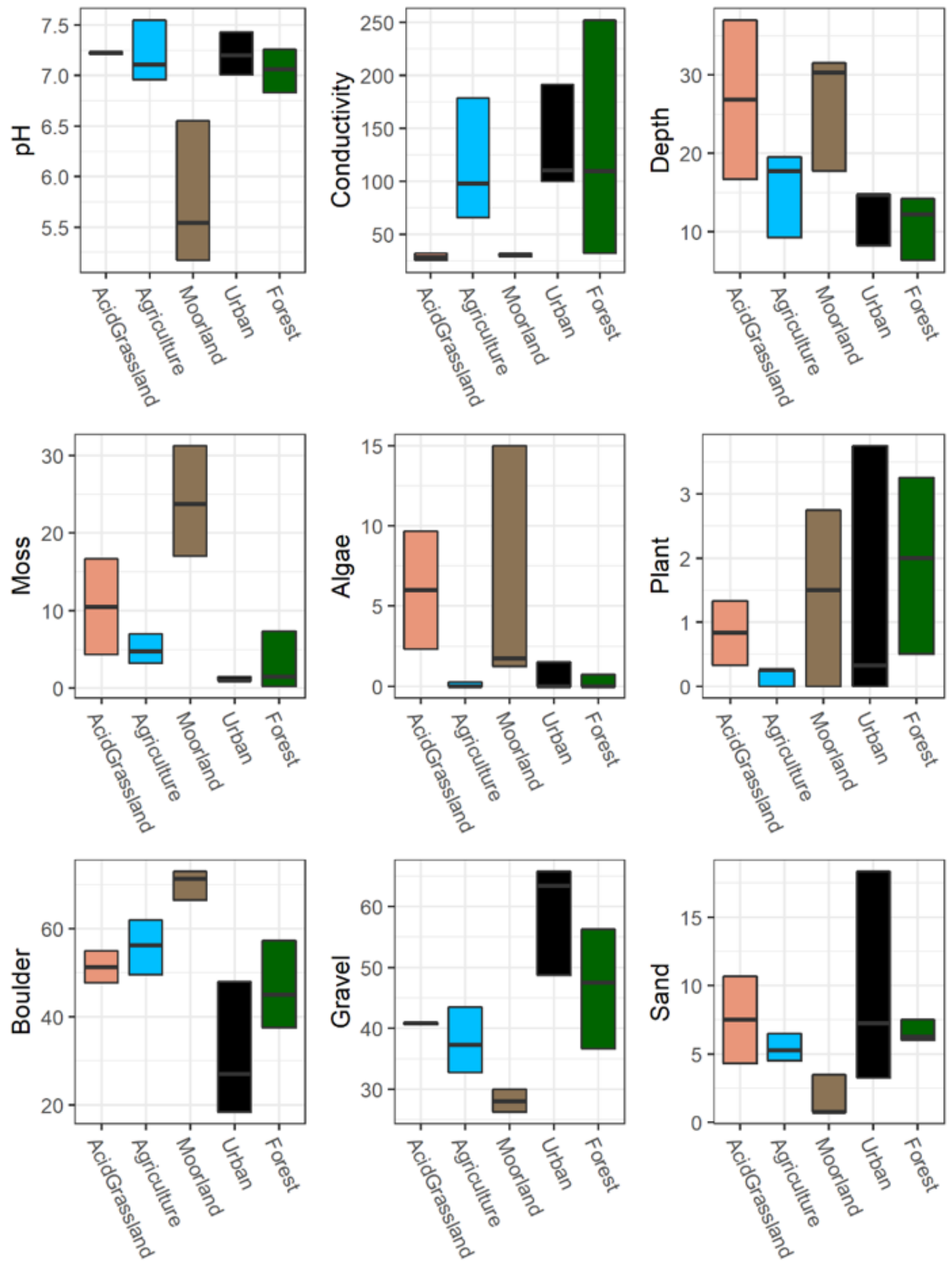

Figure 2

Box plots for each environmental variable (y-axis) sampled in the study, as a single panel. The colors in each plot match the colors in Figure 1 for each landuse type (x-axis). 
Acid Grassland

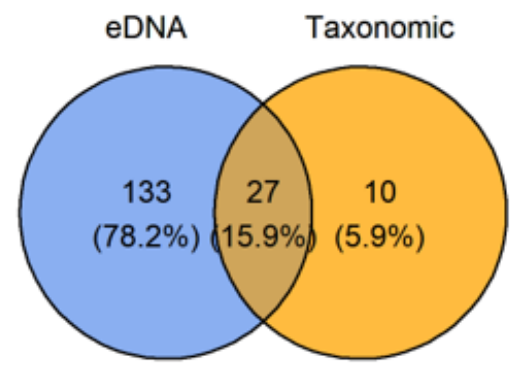

Urban

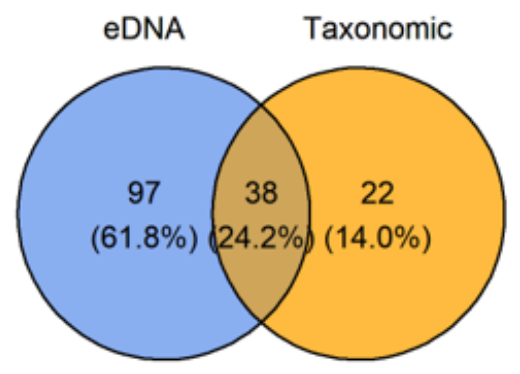

Agriculture

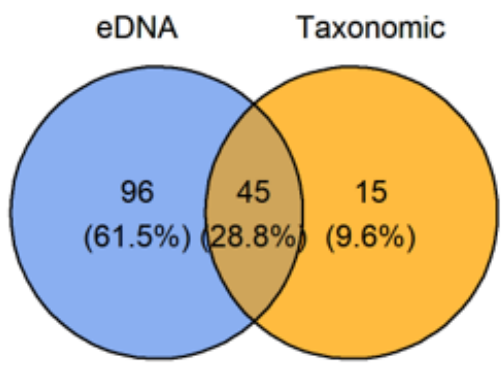

Forest

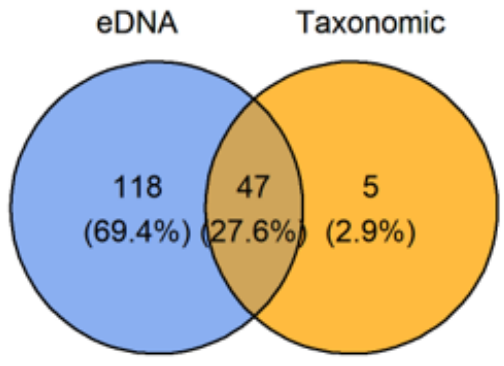

\section{Figure 3}

Box plots for each environmental variable (y-axis) sampled in the study, as a single panel. The colors in each plot match the colors in Figure 1 for each landuse type (x-axis). 

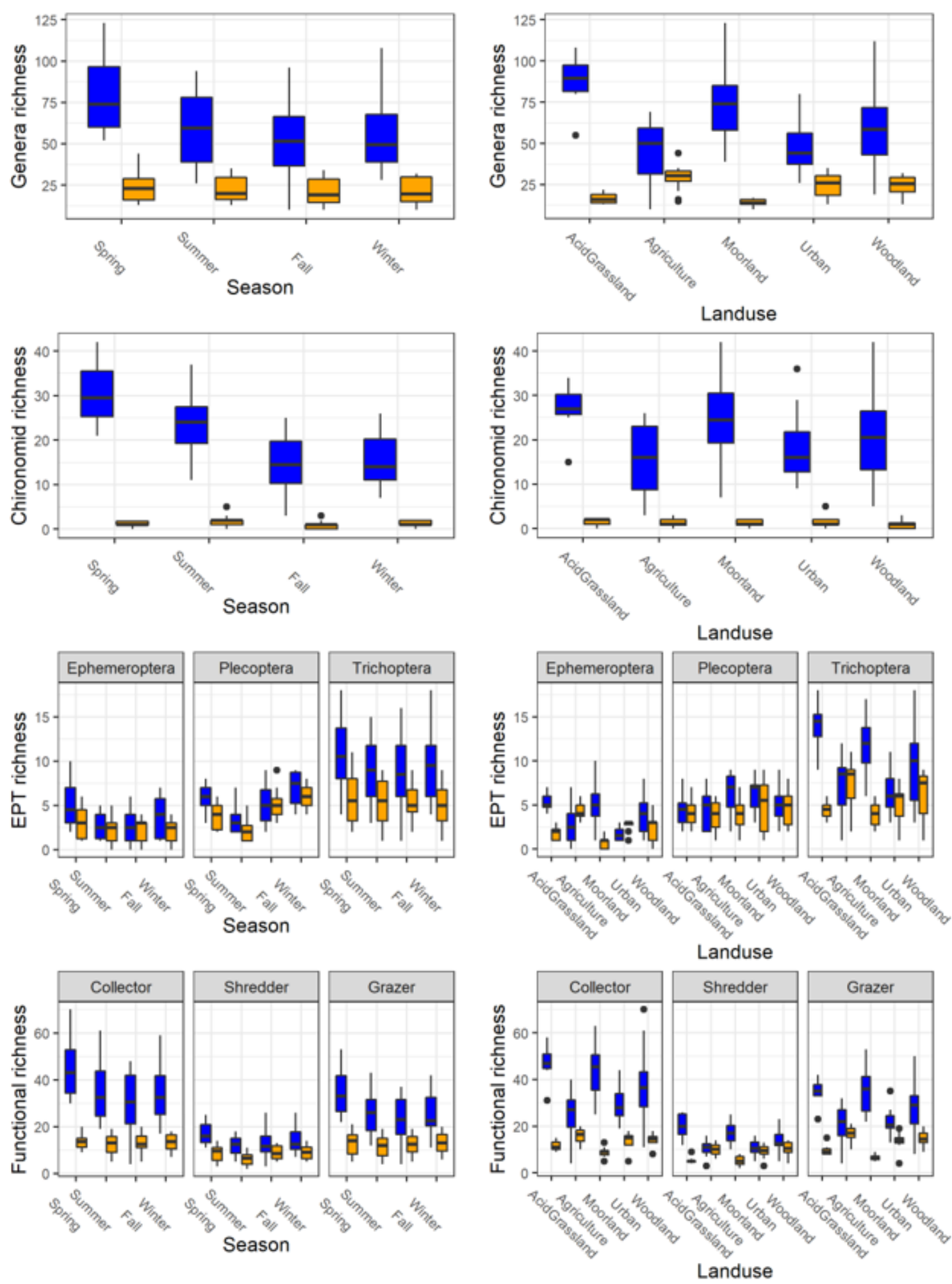

\section{Figure 4}

Box plots showing the richness diversity per season (left panels), and landuse (right panels) for genera (top), Chironomidae (second from the top), EPT (second from the bottom) and functional diversity (bottom). Blue indicates eDNA derived data and orange indicates traditional method derived data. Error bars are drawn to 1.5 * inter-quartile range (IQR), with outlier points being the data outside the 1.5 * IQR range. 


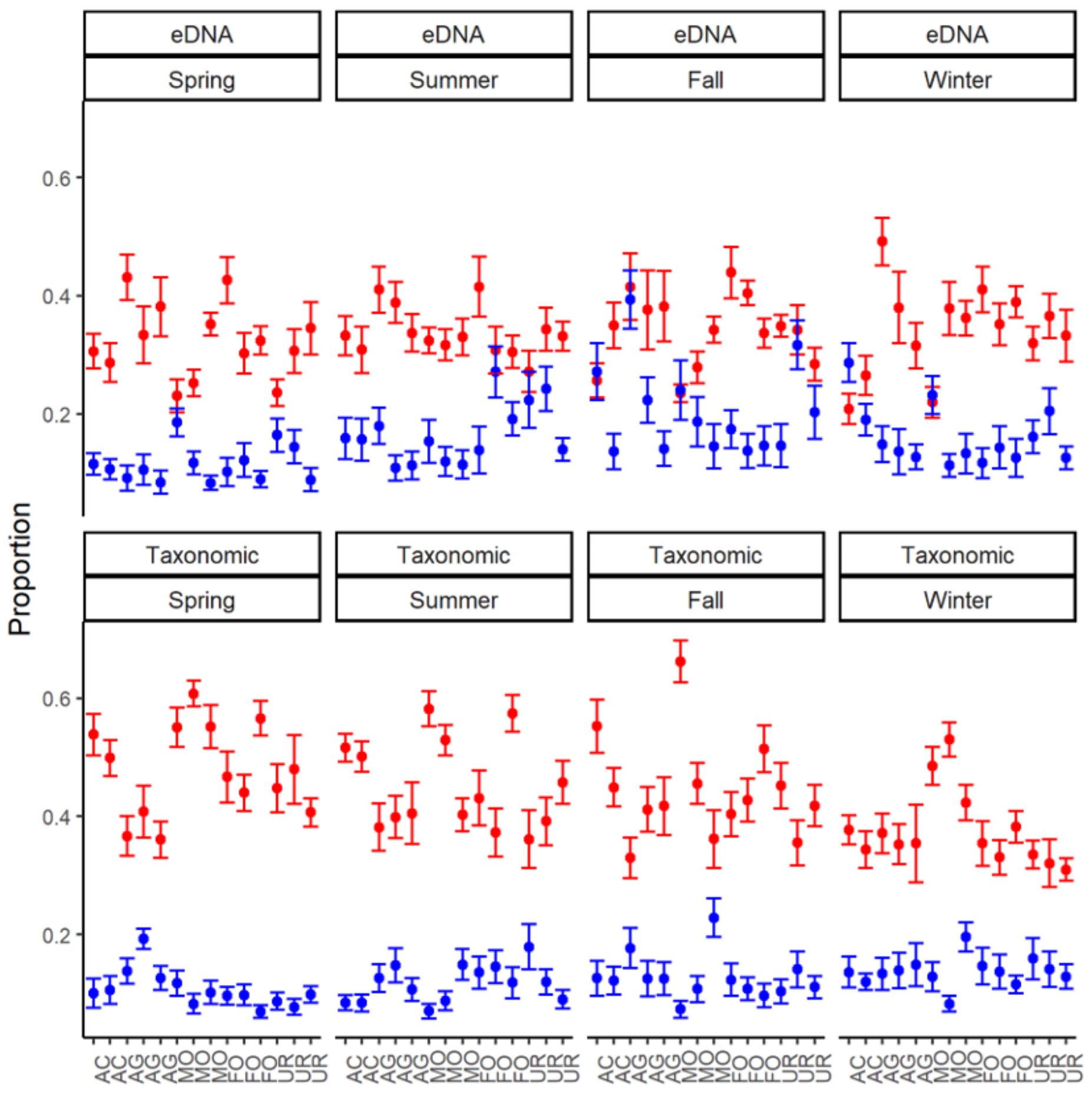

Figure 5

Beta-diversity results partitioned into turnover (red) and nestedness (blue) components. Showing differences between methods (eDNA vs Taxonomic), season (Spring, Summer, Fall, Winter), with each site provided along the $x$-axis indicating its landuse type $(A C=$ acid grassland, $A G=$ agriculture, $M O=$ moorland, FO = forest, UR = urban). Turnover was significantly greater than nestedness across landuse and seasons $(p<0.001)$, following a gls model that accounted for spatial autocorrelation in its variance structure via a pairwise distance matrix. 

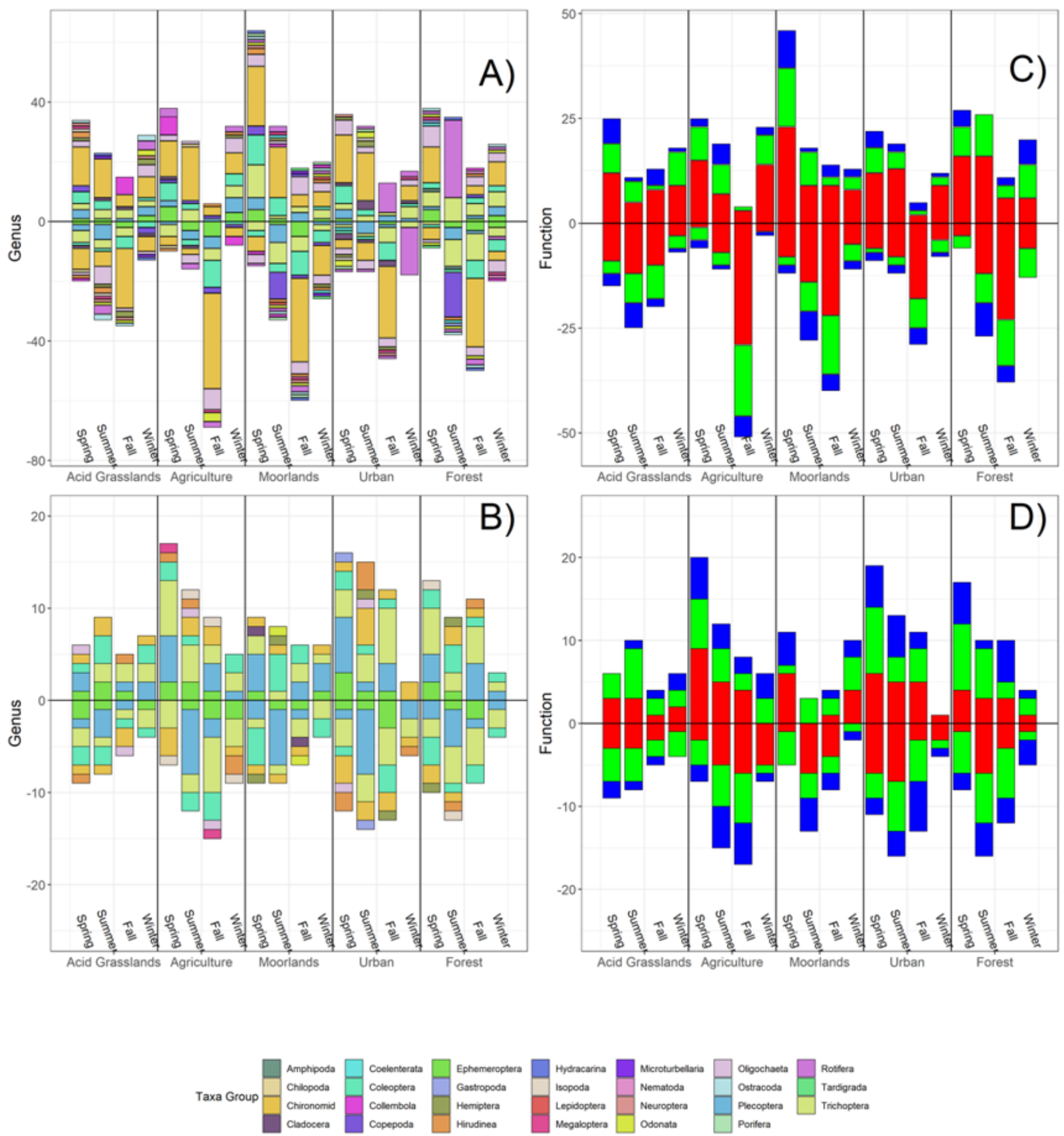

Figure 6

Change in genera richness for eDNA (A) and traditional sampling (B) and the associated change in function for eDNA (C) and traditional (D) sampling. Each subpanel is a unique landuse type showing the sequential change in genera or function whereby values above the line indicate additions in genera or function compared to the previous season and values below the horizontal line indicate loses. Colors for 
the genera plots are unique taxa groups, provided in the legend, and each value along the $y$-axis is a unique genus loss or gain. Functional group colors are: scraper $=$ blue, collector $=$ red, gatherer $=$ green .

\section{Supplementary Files}

This is a list of supplementary files associated with this preprint. Click to download.

- Seymouretalsupplementver2.docx 